\title{
Designing a Successful MOOC - An Empirical Study of the Foreign Language Courses On a MOOCs Platform
}

\section{Jia Kuang}

Yunnan Minzu University

Lan He ( $\nabla 26934738 @ q q . c o m$ )

Yunnan University of Finance and Economics https://orcid.org/0000-0003-2138-507X

\section{Original article}

Keywords: Symbolic Interactionism, Universal Design for Learning, Cognitive Load Theory, MOOCs

Posted Date: October 1st, 2021

DOI: https://doi.org/10.21203/rs.3.rs-929772/v1

License: (c) (i) This work is licensed under a Creative Commons Attribution 4.0 International License.

Read Full License 


\section{Abstract}

MOOCs have achieved great development in the last five to seven years. However, MOOCs present unique features of their own which distinguish themselves from the traditional classroom interaction. In this article, in order to find out the factors influencing the design of successful MOOCs, we examined the communication mode of MOOCs from the perspective of symbolic interactionism by combining the features of the communication mode of MOOCs as well as that of the traditional classroom interaction. Multiple linear regression analysis was conducted on 280 sample MOOCs from the foreign language courses category of a major Chinese MOOCs platform. The findings indicate that providing options for comprehension, providing options for self-regulation, coherence and temporal contiguity are the key factors for a successful design of MOOCs.

\section{Introduction}

The world of today is increasingly rendered into a technology-driven, interconnected sphere of constant change. The innovation and advancement in Internet and computer science, coupled with the current volatile external environment (mostly induced by COVID-19 pandemic), create the premise for novel development in communication, social interaction and other related aspects of human life. Against this backdrop, education, both a key embodiment and an outcome of human civilization, is inevitably undergoing great transformation. Online education, or E-learning has become an established mode of education delivery in many countries, either as a supplement to or a possible future substitute for traditional education. During the five years from 2013 to 2018, online education achieved remarkable growth in various parts of the world: Africa, 16.4\%; Latin America, 9.7\%; Asia, 8.9\%; Eastern Europe, 8.4\%; Central Europe, 6.3\%; with a projected revenue for 2021 at USD 1,189 million in Latin America, USD 16,967 million in North America, USD 5,874.8 million in Asia, USD 8.4 million in Europe, and USD 636.3 million in Africa (Ambient Insight Research, 2016; Docebo, 2018). As a prominent trend in education, the massive open online courses (MOOCs) are becoming one of the most rapidly growing online education delivery mode (Buhr et al., 2019). MOOCs provide open access to anyone who has Internet connection, which is deemed as a step forward for promoting democratization, equality, and popularization of higher education (Pouezevara and Horn, 2016).

However, as an emerging trend in technology and education, MOOCs have received a fair share of criticism. Low participant retention rate, high drop-out rate, negative emotions associated with the learning experience are among the commonly observed issues with MOOCs (Liu et al., 2020; Wan, et al., 2020). Research studies have examined the causes of the issues and proposed recommendations of how to address them from the perspective of user satisfaction, course content, interaction with peers and instructors among other parameters (Henderikx et al., 2019; Hong et al., 2017; Kaewkitipong et al., 2016; Park, 2019; Sari et al., 2020; Shahzad, et al., 2020). The research focus of most of the extant literature has been on the pros and cons of MOOCs, or its usage in various academic disciplines or environments. There are currently very limited research studies on the evaluation of MOOCs' effectiveness, level of acceptance among their viewer, and their relationship with social interaction and social psychology. 
MOOCs fall into the category of mass communication, albeit an ICT-based communication mode. Arguably, the general principles of mass communication also apply to MOOCs. However, MOOCs present unique features of their own which distinguish themselves from the traditional classroom interaction. This convergence with and divergence from the traditional communication mode could be related to the problems and issues students and teachers experience when engaging in MOOCs. MOOCs can be viewed as a type of mass communication which integrates only part of the features of face-to-face human interaction, creating certain gaps in communication. This gap could be the cause of hinderance in the effective delivery and engagement of MOOCs. Therefore, MOOCs that are well received by their viewer or users would be the ones that successfully fill in such gaps in communication. In this article, we intend to examine the communication mode of MOOCs from the perspective of social interactionism by combining the features of the communication mode of MOOCs as well as that of the traditional classroom interaction. Through the empirical analysis of the courses from the most renowned Chinese MOOCs platform with the features we obtained from the theoretical framework, we try to identify the most important features that influence the rating of MOOCs represented by the review score of each course video. We hope the research findings will provide useful references to teachers, researchers, and practitioners in the field of online education.

In the following sections, we will first provide a literature review of the symbolic interactionism, Universal Design for Learning as well as Cognitive Load Theory. Then the research framework, operational features and hypotheses will be presented. The research questions, research method, results and discussion of the quantitative analysis will also be provided. Finally, the conclusion will be drawn and the implication and future development of this study will be proposed.

\section{Literature Review}

\section{Symbolic Interactionism}

As a key theory of sociology, symbolic interactionism holds that "human beings act toward things on the basis of the meaning that the things have for them; the meaning of such things is derived from, or arises out of, the social interaction that one has with one's fellows; these meanings are handled in and modified through an interpretative process used by the person in dealing with the things he encounters" (Blumer, 1969). In this theory, a symbol is a stimulus that is abstract and arbitrary to which meaning is applied. People acquire symbols from the interaction with society or other people, which then allows them to develop a sense of self and a mind. Societies exists because people are able to interact with each other through symbols (Redmond, 2015). Examples of such symbols are languages, gestures, icons, etcetera.

Faules and Alexander (1978) pointed out that symbolic interaction was a communication theory of human behavior, which integrated traditional, behavioral and humanistic approaches to the study of communication. The core concept of this theory lies in the fact that social interaction is a process that forms human conduct instead of being a means or a setting for human conduct (Blumer, 1969). In 
effective communication, it is the symbolic human interaction that shapes our perception of ourselves and others and leads to further actions and behaviors, which is represented by the following diagram:

When applied in face-to-face communication, this cyclic interaction mostly occurs synchronously with a small part of it occurring asynchronously. In face-to-face communication, we constantly adjust our behaviors real time through other people's responses to our behaviors. Occasionally, some adjustments also take place afterwards and new behavior patterns emerge in the next round of interaction hours, days, months or even years after the first round.

However, in the online environment, esp. in the case with MOOCs, as the courses are pre-recorded and then played to the students after the recording have been finished, the interaction between the teacher and the students is almost always asynchronous, except for some limited interactive elements such as pauses, fast forward and backward, and embedded test questions and answers. Even for the interactive elements, it is highly unlikely that they will act as a qualified 'response' leading to synchronous change of behaviors of either party of the interaction in MOOCs (Hadidi and Sung, 1998; Zhang et al., 2006). Therefore, the lack of synchronous interaction between the instructor and the viewer in MOOCs is where the communication may be hindered and the transfer of meaning can be thwarted. For example, in a traditional classroom, the teachers may scan the students' facial expression and infer their level of understanding of a certain concept and then choose to either elaborate on it or only briefly mention it. In a pre-recorded course video, such interaction would be impossible, and the teachers' instruction is standardized with no change for no matter how many times the video is played. But it must also be pointed out that MOOCs possess unique features which could potentially compensate the lack of synchronous interaction (Chen and Zimitat, 2004; Ladyshewsky, 2004; Van Schaik et al, 2003). For instance, the use of animation or 3D graphics together with verbal explanation improves clarity of instruction and enhances understanding. Therefore, MOOCs present features of both face-to-face communication as well as the unique features of online video-based communication. It will be interesting to find out which features from both modes of communication exert the greatest influence on MOOCs.

\section{Face-to-Face Communication in Classroom}

In traditional classroom setting, both teaching and learning take place through face-to-face communication. Effective communication in classroom has long been a traditional central topic of a myriad of education research studies, most of which recognize the importance of instruction and curriculum design. One of the most prominent theories of these studies, Universal Design for Learning (UDL), which originated from the research in cognitive science and neuroscience, has become the new gold standard for learning design (Dalton, 2017). First developed by the Center for Applied Special Technology (CAST), UDL takes into consideration the variability of learners and design the instruction and curriculum which address this variability (CAST, 2010). UDL aims to enable effective communication in classroom based on the three learning components: 1. recognition of the information to be learned; 2 . application of strategies to process the information; and 3. engagement in the learning task (Vygotsky, 1962). Further development of UDL by Hall, Strangman, and Meyer (2003) set out three core principles: 1. 
multiple means of representation; 2. Multiple means of action and expression; 3 . multiple means of engagement. To assist in the effective design of curriculum and instructor and provide operational guidance, CAST developed the following set of guidelines for UDL implementation (CAST, 2011):

\section{Multiple Means of Representation:}

2) Provide options for language, mathematical expressions, and symbols

\section{3) Provide options for comprehension}

\section{Multiple Means of Action \& Expression: \\ 5) Provide options for expression and communication}

\section{6) Provide options for executive functions}

\section{Multiple Means of Engagement: \\ 8) Provide options for sustaining effort and persistence}

\section{9) Provide options for self-regulation}

The nine guidelines have also been recently applied to online education environment. However, considering the fact that it first originated from classroom teaching theories and practice, it is more reasonable to view them mainly as the basic principles of face-to-face interaction or communication in traditional classroom.

\section{Cognitive Load Theory and Communication in MOOCs}

In the field of instructional science, cognitive load theory (CLT) provides a way of explaining factors influencing the learning process. CLT views instruction as containing extraneous, intrinsic and germane load. Extraneous load is information presentation which contains content which is irrelevant or difficult to understand. Intrinsic load is the inherent difficulty in learners when learning new information. Germane load is the ability of learners to make association with the new knowledge and acquire the knowledge (De Jong, 2010; Sweller, 2005). High amounts of cognitive load, or high extraneous load, will hinder the learner's ability to process information and learn (Hughes et al., 2018). From the early developmental stage of this theory, CLT has been closely connected with and applied in multimedia learning. Especially, the effect of extraneous load, which is often put into practice in the instructional and curriculum design in multimedia learning environment, has become the focus of research on the effectiveness of E-learning (Bradford, 2011; Mayer and Moreno, 2010).

As a major application mode of E-learning, MOOCs present the features of multimedia learning and the principles of effective communication in multimedia are also applicable for MOOCs (Delahay and Lovett 2018). According to Mayer and Fiorella (2014), in a multimedia learning environment, the extraneous load can be effectively reduced with the following five instructional design techniques: 
1. Coherence: Eliminate extraneous material to reduce processing of extraneous material. For example, exclude interesting but irrelevant statements or graphics.

2. Signaling: Provide cues for how to process the lesson to reduce processing of extraneous material. For example, add signals that show the learner what to attend to and how to organize it.

3. Redundancy: Avoid presenting identical streams of printed and spoken words concurrently with corresponding animation. For example, present words as narration rather than as narration and on-screen text.

4. Spatial contiguity: Place printed words near corresponding parts of graphics to reduce the need for visual scanning. For example, put printed words near rather than far from corresponding parts of an illustration (on paper) or animation (on a screen).

5. Temporal contiguity: Present corresponding narration and animation at the same time to minimize the need to hold representations in memory. For example, present corresponding narration and animation simultaneously rather than successively.

Admittedly, as ramification of Mayer's seminal work, there are multiple studies exploring the methods and techniques to reduce cognitive loads in multimedia learning environment, which results in various versions of such techniques and methods (Ayres, and Sweller, 2014; Höffler and Leutner, 2007; Ibrahim et al., 2012). However, the above five principles remain the most inclusive and over-arching techniques used to reduce extraneous cognitive load in multimedia learning environment.

\section{Research Question and Research Framework}

\section{Research Questions}

This study aims to find out the design features that exert the greatest influence on the effectiveness of MOOCs and intends to answer the following question:

Out of all the design features of MOOCs, which ones are highly correlated with a MOOC which is wellreceived by its viewers (successful)?

To answer this research question, we use the review score a MOOC video receives as an index to represent the extent to which it is well-received by its viewer. For the design features of MOOCs, we combine the features of both classroom instruction and online teaching.

\section{Research Framework}

As MOOCs present features of both face-to-face communication and multimedia learning, a combination of the models for analyzing both types of communication will be conducive to conducting an in-depth examination of the factors influencing the effectiveness of MOOCs. Therefore, features extracted from the method of reducing extraneous load in CLT and the five principles of UDL are combined as the theoretical framework for our analysis. For each of the 14 features, we further operationalized them and use a descriptive index to represent them as follows: 
Table 1

Theoretical Framework and Operational Features for the Analysis of MOOCs

\section{Theoretical Framework}

1) Provide options for perception

2) Provide options for language, mathematical expressions, and symbols

3) Provide options for comprehension

4) Provide options for physical action

5) Provide options for expression and communication

6) Provide options for executive functions

7) Provide options for recruiting interest

8) Provide options for sustaining effort and persistence

9) Provide options for selfregulation

\section{Operational Features}

Provide visual, audio, digital and hard copies to students

Provide visual or translation, pre-teach vocabulary and math symbols, and point out text structures, math formula as well as scaffolding in reading to students

Provide pre-context, pre-knowledge, work examples, and application of the knowledge to the students

Allow students to use different media to complete assignments or use technology to express knowledge

Give students choice of how to respond, and provide feedback when students are working.

Provide objective and rationale for assignment, give students tips and checklists to help them work through the assignment

Provide motivation to students and break the session into segments

Help students clarify a lesson's objectives, provide different challenges to students and give feedback

Allow students to make choice, tell students the relevance of a lesson and create a classroom environment that is suitable for learning.

10) Coherence

Eliminate extraneous material to reduce processing of extraneous material.

11) Signaling

Provide cues for how to process the lesson to reduce processing of extraneous material

12) Redundancy

Avoid presenting identical streams of printed and spoken words concurrently with corresponding animation.

13) Spatial contiguity

Place printed words near corresponding parts of graphics to reduce the need for visual scanning

14) Temporal contiguity

Present corresponding narration and animation at the same time to minimize the need to hold representations in memory.

\section{Research Method}

For the purpose of this study, we chose the foreign language course videos offered on one of the most renowned MOOCs platforms of China. The platform contains thousands of MOOCs developed by 
universities across China. The disciplines of the MOOCs cover arts and sciences, humanities, law, business and management, engineering as well as vocational and continued education. As of January 13,2021 , under the category of Foreign Languages Courses, there are over 384 related courses. We chose only the courses in this category so as to ensure the control of the confounding factors to the greatest extent. For each course, an introduction to the course, a syllabus, and a series of course videos are provided by the instructors as compulsory elements. The platform also offers the functions of forum, assignments and tests, bulletin boards for instructors to upload related materials onto the platform and have interaction with the viewer. In addition, under course function, instructors may also optionally upload teaching materials in various media, including downloadable PowerPoint presentation and Wordprocessed notes. Registered users of the platform may enroll in most of the course free of charge and give a review score of 1-5 to each course. The final review score, which is an average of all ratings given by the users, represents the level of how well-received a course is.

Based on the research framework, we propose the following hypotheses for testing in this study:

H1. Providing visual, audio, digital and hard copies to students is positively correlated with the review score of a course video.

H2. Providing visual or translation, pre-teach vocabulary and math symbols, and pointing out text structures, math formula as well as scaffolding in reading to students is positively correlated with the review score of a course video.

H3. Providing pre-context, pre-knowledge, work examples, and application of the knowledge to the students is positively correlated with the review score of a course video.

H4. Allowing students to use different media to complete assignments or use technology to express knowledge is positively correlated with the review score of a course video.

H5. Giving students choice of how to respond, and providing feedback when students are working is positively correlated with the review score of a course video.

H6. Providing objective and rationale for assignment and giving students tips and checklists to help them work through the assignment are positively related with review score of a course video.

H7. Providing motivation to students and breaking the session into segments are positively correlated with the review score of a course video.

H8. Helping students clarify a lesson's objectives, providing different challenges to students and giving feedback are positively correlated with the review score of a course video.

H9. Allowing students to make choice, telling students the relevance of a lesson and creating a classroom environment that is suitable for learning are positively correlated with the review score of a course video. 
H10. Eliminating extraneous material to reduce processing of extraneous material is positively correlated with the review score of a course video.

$\mathrm{H} 11$. Providing cues for how to process the lesson to reduce processing of extraneous material is positively correlated with the review score of a course video.

H12. Avoiding presenting identical streams of printed and spoken words concurrently with corresponding animation is positively correlated with the review score of a course video.

H13. Placing printed words near corresponding parts of graphics to reduce the need for visual scanning is positively correlated with the review score of a course video.

$\mathrm{H} 14$. Presenting corresponding narration and animation at the same time to minimize the need to hold representations in memory is positively correlated with the review score of a course video.

In this project, for every course in the category Foreign Languages Courses, we assigned two graduate students who have had extensive experience with MOOCs as independent evaluators to give a rating of 1-5 for each of the above 14 features. The rating of 1 indicates that this feature presents itself very weakly in a course, and the rating of 5 indicates that a certain feature has a very strong presence in a course. The average score of the two evaluators for each feature of each course was calculated as the final score for that feature of the course. In order to eliminate the potential bias in the ratings, we made sure that both evaluators did not see the review score before they finished providing the ratings for the features.

The following principles were followed by both evaluators when rating the MOOCs in the sample:

1. If the instructor provides downloadable files or materials in the course module of the platform besides course video, it should be regarded as providing hard copies to the students, which will result in higher score for feature 1.

2. In the assignment module of the course, if the instructor provides various types of assignments with audio, html text, and video or asks the students to upload their recorded audio files in addition to online written assignments, the evaluators will give a higher score to feature 4 for this course.

3. In the forum module, if there are extensive interaction between the instructor and the students/viewers, then the score of feature 5 for this course will be correspondingly higher. The higher score is given to those courses with not only just interaction in the forum, but also other online-interaction conducted through instant messaging or emails as well as off-line interaction.

4. In the course video, if the instructor asks many questions and provides answers afterwards or gives small test questions during the video, such courses will receive a higher score for feature 8.

5. For course videos without using any animation, its score for feature 14 will be 1 . 
6. For any courses taught by the same instructor from the same university, only one of them will be selected into our sample and rated.

After data collection was finished, we used multiple linear regression as the quantitative analysis method for this study. According to Saunders et al. (2012), regression analysis is used to predict the value of a dependent variable given the values of one or more independent variables by calculating a regression equation, which corresponds to the situation of this research. We collected a total of 280 samples from the dataset and those which either did not have review score or had an outlier score were excluded. After the ratings for all 14 features as well as the review scores were collected, multiple linear regression analysis was conducted with IBM SPSS Version 25 and the results are shown in the next section.

\section{Results And Discussion}

As Table 1 shows, an $R^{2}$ value of 0.301 is obtained, indicating that the model accounts for $30.1 \%$ of the variance of the review score, which is statistically significant $(p<0.05)$.

Table 2

The regression summary of the data

\begin{tabular}{|c|c|c|c|c|c|c|c|c|c|}
\hline \multicolumn{10}{|c|}{ Model Summaryb } \\
\hline \multirow[t]{2}{*}{ Model } & \multirow[t]{2}{*}{$\mathrm{R}$} & \multirow{2}{*}{$\begin{array}{l}\mathrm{R} \\
\text { Square }\end{array}$} & \multirow{2}{*}{$\begin{array}{l}\text { Adjusted } \\
\text { R Square }\end{array}$} & \multirow{2}{*}{$\begin{array}{l}\text { Std. Error } \\
\text { of the } \\
\text { Estimate }\end{array}$} & \multicolumn{5}{|c|}{ Change Statistics } \\
\hline & & & & & $\begin{array}{l}\text { R } \\
\text { Square } \\
\text { Change }\end{array}$ & $\begin{array}{l}\mathrm{F} \\
\text { Change }\end{array}$ & $\mathrm{df} 1$ & df2 & $\begin{array}{l}\text { Sig. F } \\
\text { Change }\end{array}$ \\
\hline 1 & $.549^{a}$ & .301 & .264 & .1231 & .301 & 8.149 & 14 & 265 & .000 \\
\hline
\end{tabular}

Table 3 indicates that the overall regression mode is significant, $\mathrm{F}(14,265)=8.15, p<0.05, R^{2}=0.301$.

Table 3

ANOVA analysis of the data

\begin{tabular}{|lllllll|}
\hline \multicolumn{1}{|l|}{ ANOVAa } & Sum of Squares & $\mathrm{df}$ & Mean Square & $\mathrm{F}$ & Sig. \\
\hline \multicolumn{1}{|l}{ Model } & Regression & 1.729 & 14 & .123 & 8.149 & $.000 \mathrm{~b}$ \\
\cline { 2 - 5 } & 4.015 & 265 & .015 & & \\
\hline & Residual & & & & \\
\hline
\end{tabular}

Table 4 indicates that feature $3,9,10$, and 14 have a statistically significant correlation with review score $(p<0.05)$ where the contribution of feature 9 is the greatest $(\beta=0.413)$ followed by feature $10(\beta=0.182)$, feature $3(\beta=0.122)$ and feature $14(\beta=0.114)$. The semi-partial correlation shows that the unique contribution of feature 9 is the greatest. 
Table 4

Coefficient Summary of the Data

\begin{tabular}{|c|c|c|c|c|c|c|c|c|c|}
\hline \multicolumn{10}{|c|}{ Coefficients $^{a}$} \\
\hline \multicolumn{2}{|c|}{ Model } & \multicolumn{2}{|c|}{$\begin{array}{l}\text { Unstandardized } \\
\text { Coefficients }\end{array}$} & \multirow{2}{*}{$\begin{array}{l}\text { Standardized } \\
\text { Coefficients } \\
\text { Beta }\end{array}$} & \multirow[t]{2}{*}{$\mathrm{t}$} & \multirow[t]{2}{*}{ Sig. } & \multicolumn{3}{|c|}{ Correlations } \\
\hline & & B & $\begin{array}{l}\text { Std. } \\
\text { Error }\end{array}$ & & & & $\begin{array}{l}\text { Zero- } \\
\text { order }\end{array}$ & Partial & Part \\
\hline \multirow[t]{15}{*}{1} & (Constant) & 4.365 & .075 & & 58.274 & .000 & & & \\
\hline & Feature1 & -.016 & .010 & -.096 & -1.606 & .110 & .080 & -.098 & -.082 \\
\hline & Feature2 & .003 & .007 & .027 & .421 & .674 & .197 & .026 & .022 \\
\hline & Feature3 & .017 & .008 & .122 & 1.998 & .047 & .297 & .122 & .103 \\
\hline & Feature4 & .010 & .008 & .077 & 1.195 & .233 & .176 & .073 & .061 \\
\hline & Feature5 & .007 & .008 & .049 & .825 & .410 & .198 & .051 & .042 \\
\hline & Feature6 & .003 & .009 & .022 & .349 & .727 & .052 & .021 & .018 \\
\hline & Feature7 & -.003 & .007 & -.024 & -.393 & .695 & .191 & -.024 & -.020 \\
\hline & Feature8 & -.000 & .007 & .000 & -.005 & .996 & .232 & .000 & .000 \\
\hline & Feature9 & .057 & .009 & .413 & 6.347 & .000 & .483 & .363 & .326 \\
\hline & Feature10 & .021 & .007 & .182 & 3.171 & .002 & .157 & .191 & .163 \\
\hline & Feature11 & -.014 & .012 & -.071 & -1.143 & .254 & .059 & -.070 & -.059 \\
\hline & Feature12 & .000 & .004 & .002 & .036 & .971 & .059 & .002 & .002 \\
\hline & Feature13 & .006 & .013 & .023 & .432 & .666 & .064 & .027 & .022 \\
\hline & Feature14 & .013 & .006 & .114 & 2.113 & .036 & .189 & .129 & .109 \\
\hline
\end{tabular}

Figure 2 and Fig. 3 indicate that there is a linear relation between the features and the review score.

Based on the above results, we reject the null hypothesis for $\mathrm{H} 3, \mathrm{H} 9, \mathrm{H} 10$, and $\mathrm{H} 14$, however, feature 1,2 , $4,5,6,7,8,11,12$, and 13 do not present a strong enough correlation with review score.

H3: Providing pre-context, pre-knowledge, work examples, and application of the knowledge to the students is positively correlated with the review score of a course video. In the current model, $\mathrm{H} 3$ is supported and we found that most of the MOOCs with high review scores provided an entire chapter of introduction to the courses where the background and pre-knowledge of the course was included in the format of video, PowerPoint presentation or Word file as the first part of the course. In addition, courses with real-life application and examples of the knowledge and theories taught in the course also tend to be more well-received by the viewer. MOOCs which simply transform single section of classroom teaching 
into a video form without providing much pre-context or pre-knowledge tend to receive a lower review score.

H9: Allowing students to make choice, telling students the relevance of a lesson and creating a classroom environment that is suitable for learning are positively correlated with the review score of a course video. $\mathrm{H} 9$ is a feature that facilitates self-regulation of the students. We found that most the samples with higher scores managed to simulate interaction with students by asking various questions during the process of the course and then providing answers. At the same time, the instructors also tend to use humorous language and in-class exercises to encourage students to learn. The instructors in such courses also appeared more amicable and approachable when talking to the students in the video. Both the interaction and the instructors' attitude helped create a good ambience for learning.

H10. Eliminating extraneous material to reduce processing of extraneous material is positively correlated with the review score of a course video. Most of the MOOCs in our samples used various patterns, tags, aminations for the background of the video, which in fact distracted the attention of the viewers who need to distinguish such information from the key knowledge of the course. As a matter of fact, a lot of the course videos with good performance on other features may still get a lower review score due to a 'messy style' of the course video. A simple, single color background of the video with minimal interruptive elements will be the ideal mode for learning in MOOCs.

H14: Presenting corresponding narration and animation at the same time to minimize the need to hold representations in memory is positively correlated with the review score of a course video. In our sample, most of the courses did present corresponding narration and animation at the same time. However, there are still some courses with no animation at all or simply present the animation without narration. When animation is not used, the advantages of video are not fully taken of, and the course will not be too much different from traditional classroom courses. In addition, playing animation without narration could create hinderance in the accurate understanding of the animation and the meaning it intends to convey.

Taken together, we may infer from the data analysis that two features of the traditional classroom interaction based on UDL (provide options for comprehension and provide options for self-regulation) as well as two features of E-learning based on Cognitive Load Theory (coherence and temporal contiguity) are the key factors for a successful design of MOOCs.

\section{Conclusion}

When analyzing E-learning as represented by MOOCs, it is imperative that we do not delineate it mechanically from traditional classroom teaching. MOOCs both simulate and innovate traditional classroom courses by combining the strong features of E-learning and face-to-face teaching. The techniques of traditional classroom teaching which are now embedded in online learning environment will exert very little influence on the success of a MOOC. For example, in traditional classrooms, providing visual, audio, digital and hard copies to students; offering visual or translation, pre-teach vocabulary as well as scaffolding; allowing students to use different media and technology to complete assignments or 
express knowledge are all deemed to be important ways to enrich the delivery of a course. However, in online environment, such features or requirements are already the inherent elements of E-learning platforms. MOOCs automatically provide course materials in various media or even eliminate the need of hard copies. The visual or translation, vocabulary as well as scaffolding are included in the course video for students to watch and learn at the same time, which greatly reduce the time of instruction. Students participating in MOOCs are already equipped with the necessary computer and information technology literacy and skills to engage in such courses. Therefore, the various modes of "enriching or diversifying" an off-line course are all easily integrated into online platforms and became the "taken-for-granted" elements of a MOOC. That is to say, they are regarded as a "default" part of MOOCs. When MOOCs present such features, it will not make them more welcome by the viewers but if a MOOC does not provide such functions, then the course will be deemed as having major problems by the viewers.

For those features of traditional classroom teaching that are specific to face-to-face interaction, they also do not have a great influence on how well-received a MOOC is. For example, providing feedback to students, explaining assignments, providing motivation to students, clarifying the objective of a lesson and providing different challenges to students do not seem to increase the review score of a MOOC. This is because those features are very specific to offline courses where a lot of face-to-face synchronous communication needs to be involved. For instructors, it is very uncomfortable for them to engage in a pep-talk to only a camera. In addition, when not knowing the exact condition of the audience, it is also quite difficult to provide proper challenges to them. Most of such problems were caused by the asynchronous communication of MOOCs where the features of synchronous communication in classrooms cannot be well-simulated.

However, for those features of traditional classroom teaching which could fill in the gap of communication in online environment, they do seem to exert an influence on the success of a MOOC. For instance, providing pre-context, pre-knowledge, work examples and application of the knowledge to For instance, providing pre-context, pre-knowledge, work examples, and application of the knowledge to the students, as well as telling the students the relevance of a lesson and creating a classroom environment suitable for learning are techniques which reduce the unease a viewer could experience when participating in a MOOC. As MOOCs are open courses, the viewers could come from various education, demographic, and social background, which is one of the most salient difference from traditional, homogeneous classes. Therefore, by providing pre-context, pre-knowledge, examples and application of knowledge, it will help the viewers establish their relationship with the course and how they will approach this course. In the online environment, this will greatly increase efficiency and reduce unnecessary waste of time, as the viewers may choose to stay for a leave a certain course. Once they participate in the course, when they feel that the instructor engages with them by creating a good ambience for the class, they will give a higher review score to it. Thus, these two features act on a MOOC by filling in important gaps between classroom teaching and online learning.

For features of reducing extraneous cognitive load, their effects on the review score also differ greatly. Providing cues for how to process the lesson to reduced processing of extraneous materials is almost 
non-existent in all of the courses we studied. It seems that most of the instructors did not realize that the extraneous materials in the course video or course design could cause problems, and thus no cues or pointers were provided on how to reduce the extraneous information. In addition, as the courses are mostly foreign language courses, providing identical streams of printed and spoken words concurrently with corresponding animation appeared to be the common practice to assist understanding for spoken words in foreign languages. Very few courses met the requirement of non-redundancy which are mostly foreign culture related classes taught in Mandarin. The same logic also applies to the spatial continuity where placing printed words near corresponding parts of graphics to reduce the need for visual scanning is already a well-accepted and applied rule. Almost every course video was designed by closely following this principle. However, eliminating extraneous materials and presenting corresponding narration and animation at the same time do seem to have an effect on review score of a course. Although on the instruction side, there appeared to be a lack of appreciation of such principles, the viewers or students tend to give a better review to courses with the minimal amount of extraneous material and the maximal

amount of assistance for short-term memory. This interesting dichotomy shows that the instructors and students may have different perception of the presentation mode of a course.

Relating back to the theory, indeed we found that the communication mode in MOOCs is an asynchronous symbolic interaction. Among the features of face-to-face interaction and online communication, those features which fill in the gap of asynchronous interaction and enhances students understanding and learning are highly correlated with a MOOC which is well-received by its viewers. This study provides useful references for educators, researchers, decision-makers and practitioners in Elearning, social interaction and ICT. However, the caveat will be to take into consideration of cultural differences that could potentially be a confounding factor in this research. For instance, the viewers of the MOOCs in our sample are mostly Chinese students who are used to Chinese pedagogy and education philosophy. Therefore, features such as providing motivations to students, giving choice of how to respond, providing objective and rationale for assignments could have much less of an influence on Chinese students than they would on students from say, Western countries. Chinese students as a group tend to be more self-motivated to engage in learning activities and thus such features do not have a strong effect on Chinese students. Therefore, further research may conduct comparative analysis and apply the model to include students from various countries and background to test the robustness of it. Longitudinal studies which track the development of MOOCs and viewers' reaction to them will also be a direction that's worth exploring.

\section{Abbreviations}

MOOCs: Massive Open Online Courses

ICT: information and communications technology

UDL: Universal Design for Learning

CAST: Center for Applied Special Technology 
CLT: cognitive load theory

IBM: International Business Machines Corp

SPSS: Statistical Package for the Social Sciences

\section{Declarations}

Funding: Humanities and Social Sciences Foundation of the Ministry of Education of China. Grant Number: 18YJC760035

Conflicts of interest/Competing interests: None.

Availability of data and material: All data and materials are available upon request.

Author's contributions: Design of the research, data collection, qualitative analysis and writing up of the manuscript.

Availability of data and material: All data and materials were obtained with informed consent and will be made available on request. The data are publicly available at https://www.icourse163.org/channel/2002.htm

\section{Funding:}

The author receives Humanities and Social Sciences Research Grant from the Ministry of Education of China (18YJC760035)

\section{Competing interests:}

The authors declare that they have no competing interests

Authors' contributions

Jia Kuang carried out the research design, literature search and review and drafted the manuscript. Lan He conducted the research process, collected and analyzed the data and performed the statistical analysis.

\section{Acknowledgements:}

The author would like to thank the two annotators for their conscientious and diligent work for this research project.

\section{References}


1. Ambient Insight Research. International learning market research. http://www. ambientinsight.com/Reports/eLearning.aspx Accessed 26 October, 2020.

2. Ayres, P., \& Sweller, J. (2014). The split-attention principle in multimedia learning. The Cambridge handbook of multimedia learning, 2. https://doi.org//10.1017/СB09780511816819.009 Accessed 3 September, 2020.

3. Blumer, H. (1969). Symbolic interactionism. Englewood Cliffs, NJ: Prentice-Hall

4. Bradford, G. R. (2011). A relationship study of student satisfaction with learning online and cognitive load: Initial results. Internet and Higher Education, Vol. 14 No(4), 217-226

5. Buhr, E. E., Daniels, L. M., \& Goegan, L. D. (2019). Cognitive appraisals mediate relationships between two basic psychological needs and emotions in a massive open online course. Computers in Human Behavior, 96, 85-94https://doi.org/10. 1016/j.chb.2019.02.009

6. CAST. UDL and UD Provisions in the Higher Education Opportunity Act (P.L. 110-315). Washington, D.C.: U.S. Department of Education. http://www.udlcenter.org/advocacy/referencestoUDL/HEOA Access 17 May, 2020.

7. Chen, N., \& Zimitat, C. (2004). Differences in the quality of learning outcomes in a F2F blended versus wholly online course. Beyond the comfort zone: Proceedings of the 21st ASCILITE Conference, Perth, 175-179.

8. Dalton, D. (2017). Beyond universal design for learning: Guiding principles to reduce barriers to digital and media literacy competence. Journal of Media Literacy Education, 9(2), 17-29

9. De Jong, T. (2010). Cognitive load theory, educational research, and instructional design: some food for thought. Instructional Science, Vol. 38 No(2), 105-134

10. Delahay, A. B., \& Lovett, M. C. (2018). Multimedia learning principles at scale predict quiz performance. In Proceedings of the Fifth Annual ACM Conference on Learning at Scale (L@S '18). Association for Computing Machinery, New York, NY, USA, Article 36, 1-4.

DOl:https://doi.org/10.1145/3231644.3231694

11. Docebo. e-Learning trends 2018. https://www.docebo.com/resource/whitepaper-elearning-trends2018 Accessed 17 June, 2020.

12. Faules, D. F., \& Alexander, D. C. (1978). Communication and social behavior: A symbolic interaction perspective. Reading, MA: Addison-Wesley Publishing

13. Hadidi, R., \& Sung, C. (1998). Students' acceptance of Web-based course offerings: an empirical assessment, in: Proceedings of the AMCIS Conference, Baltimore, MD.

14. Hall, T., Strangman, N., \& Meyer, A. (2003). Differentiated Instruction and Implications for UDL Implementation. Wakefield, MA: National Center on Accessing the General Curriculum.

http://aim.cast.org/learn/historyarchive/backgroundpapers/differentiated Accessed 2 November, 2020.

15. Henderikx, M., Lohr, A., \& Kalz, M. (2019). Enjoyed or bored? A study into achievement emotions and the association with barriers to learning in MOOCs [Paper presentation]. Transforming Learning with Meaningful Technologies (pp. 15-27). Springer. https:// doi.org/10.1007/978-3-030-29736-7_2 
16. Höffler, T. N., \& Leutner, D. (2007). Instructional animation versus static pictures: A meta-analysis. Learning and Instruction, 17(6), 722-738. https://doi.org//10.1016/j.learninstruc.2007.09.013

17. Hong, J., Tai, K., Hwang, M., Kuo, Y., \& Chen, J. (2017). Internet cognitive failure relevant to users' satisfaction with content and interface design to reflect continuance intention to use a government elearning system. Computers in Human Behavior, 66, 353-362

18. Hughes, C., Costley, \& Lange, J., C. (2018). The effect of self-regulated learning and cognitive load on beginning to watch and completing video lectures at a cyber-university. Interact. Technol. Smart Educat, 15, 220-237. doi: 10.1108/itse-03-2018-0018

19. Ibrahim, M., Antonenko, P. D., Greenwood, C. M., \& Wheeler, D. (2012). Effects of segmenting, signalling, and weeding on learning from educational video. Learning, media and technology, 37(3), 220-235. https://doi.org//10.1080/17439884.2011.585993

20. Kaewkitipong, L., Chen, C. C., \& Ractham, P. (2016). Using social media to enrich information systems field trip experiences: Students' satisfaction and continuance intentions. Computers in Human Behavior, 63, 256-263

21. Ladyshewsky, R. (2004). E-learning compared with face-to-face: Differences in the academic achievement of postgraduate business students. Australasian Journal of Educational Technology, 20(3), 316-336

22. Liu, B. W., Xing, W. L., Zeng, Y. F., \& Wu, Y. H. (2020). Quantifying the influence of achievement emotions for student learning in MOOCs. Journal of Education Computing, 0(0), 1-24

23. Mayer, R. E., \& Moreno, R. (2010). Techniques that reduce extraneous cognitive load and manage intrinsic cognitive load during multimedia learning. In Plass, J. L., Moreno, R., \& Brünken, R.red Cognitive Load Theory (pp. 131-152). New York: Cambridge

24. Mayer, R. E., \& Fiorella, L. (2014). Principles for reducing extraneous processing in multimedia learning: Coherence, signaling, redundancy, spatial contiguity, and temporal contiguity principles. In Mayer, R. E.red Cambridge handbooks in psychology. The Cambridge handbook of multimedia learning (pp. 279-315). Cambridge University Press.

https://doi.org/10.1017/CB09781139547369.015

25. Park, T., \& Lim, C. (2019). Design principles for improving emotional affordances in an online learning environment. Asia Pacific Educ. Rev, 20, 53-67. https://doi.org/10.1007/s12564-018-9560-7

26. Pouezevara, S. R., \& Horn, L. J. (2016). MOOCs and Online Education: Exploring the Potential for International Educational Development. RTI Press Publication No. OP-0029-1603. Research Triangle Park, NC: RTI Press. http://dx.doi.org/10.3768/ rtipress.2016.op.0029.1603

27. Redmond, M. V. (2015). "Symbolic Interactionism". English Technical Reports and White Papers. 4. http://lib.dr.iastate.edu/engl_reports/4 Accessed December 16, 2020.

28. Sari, A. R., Bonk, C. J., \& Zhu, M. (2020). MOOC instructor designs and challenges: what can be learned from existing MOOCs in Indonesia and Malaysia? Asia Pacific Educ. Rev, 21, 143-166. https://doi.org/10.1007/s12564-019-09618-9 
29. Shahzad, F., Xiu, G., Khan, I., et al. (2020). The moderating role of intrinsic motivation in cloud computing adoption in online education in a developing country: a structural equation model. Asia Pacific Educ. Rev, 21, 121-141. https://doi.org/10.1007/s12564-019-09611-2

30. Saunders, M., Lewis, P., \& Thornhill, A. (2012). Research Methods for Business Students. Harlow: Pearson Education Ltd.

31. Sweller, J. (2005). "Implications of cognitive load theory for multimedia learning. In Mayer", R. E. (Ed.), The Cambridge Handbook of Multimedia Learning (pp. 19-30). New York, NY: Cambridge University Press

32. Van Schaik, P., Barker, P., \& Beckstrand, S. (2003). A Comparison of On-Campus and Online Course Delivery Methods in Southern Nevada. Innovations in Education \& Teaching International, 40(1), 515

33. Vygotsky, L. (1962). Thought and language. Cambridge, MA: Massachusetts Institute of Technology

34. Wan, L. Y., Xie, S. M., \& Shu, A. (2020). Toward an understanding of university students' continued intention to use MOOCs: When UTAUT model meets TTF Model. Sage Open, July-September 2020: $1-15$.

35. Zhang, D. S., Zhou, L. N., Briggs, R. O., \& Nunamaker, J. F. J., and (2006). Instructional video in elearning: Assessing the impact of interactive video on learning effectiveness. Information and Management, 43(2006), 15-27.

\section{Figures}

\section{Cyclical Model of Interactions between Self and Others} Behaviors

Self

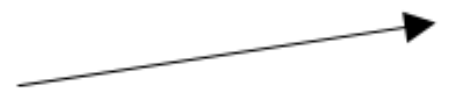

Behavior

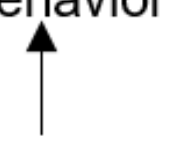

Perception of Other's

Responses

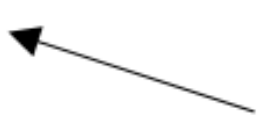

Other People's Responses

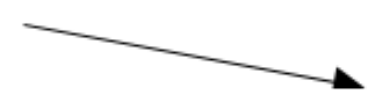

Other People's Perception of the

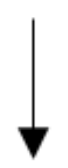

Other People's Impression of the "Self"

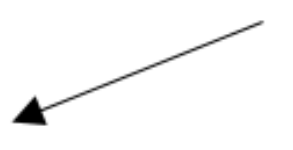

\section{Figure 1}


Mead's cyclical model of interactions between self and others as summarized by Redmond (2015)

Normal P-P Plot of Regression Standardized Residual

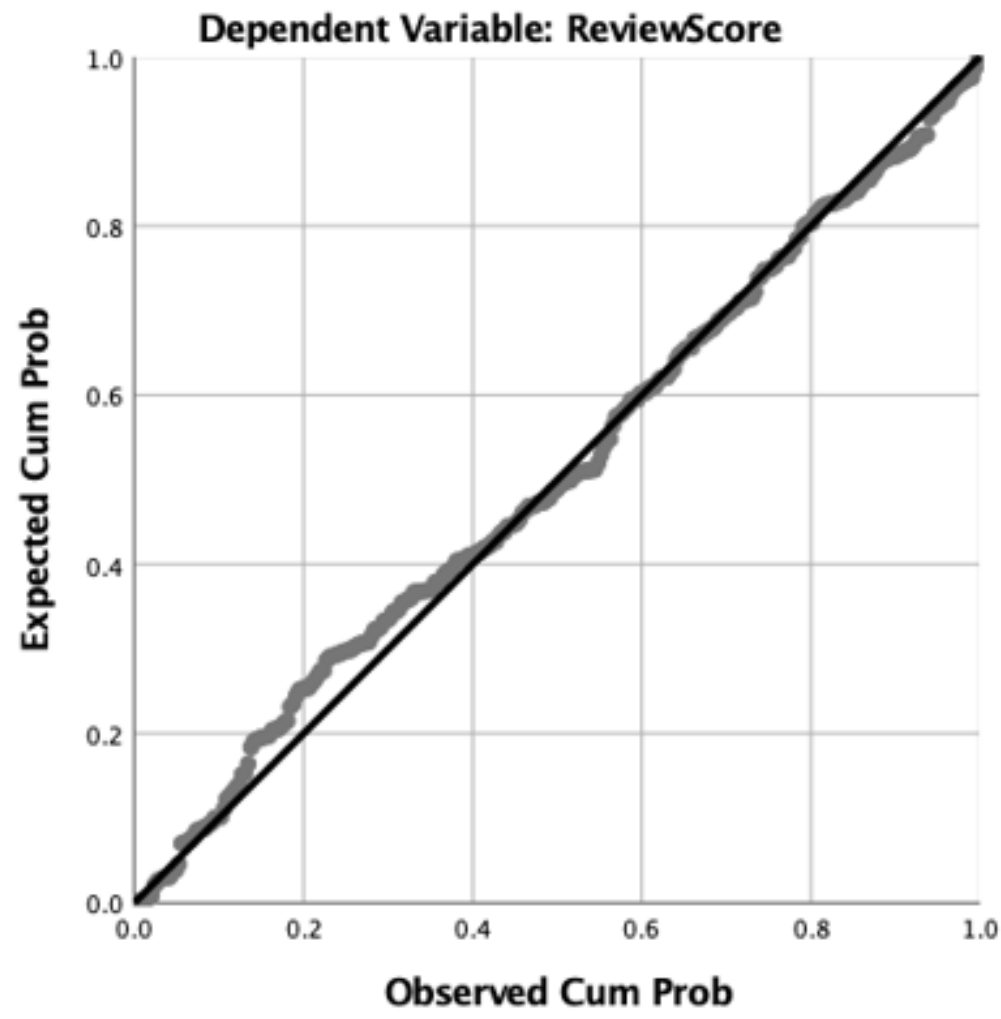

Figure 2

Normal P-P Plot of the Data 


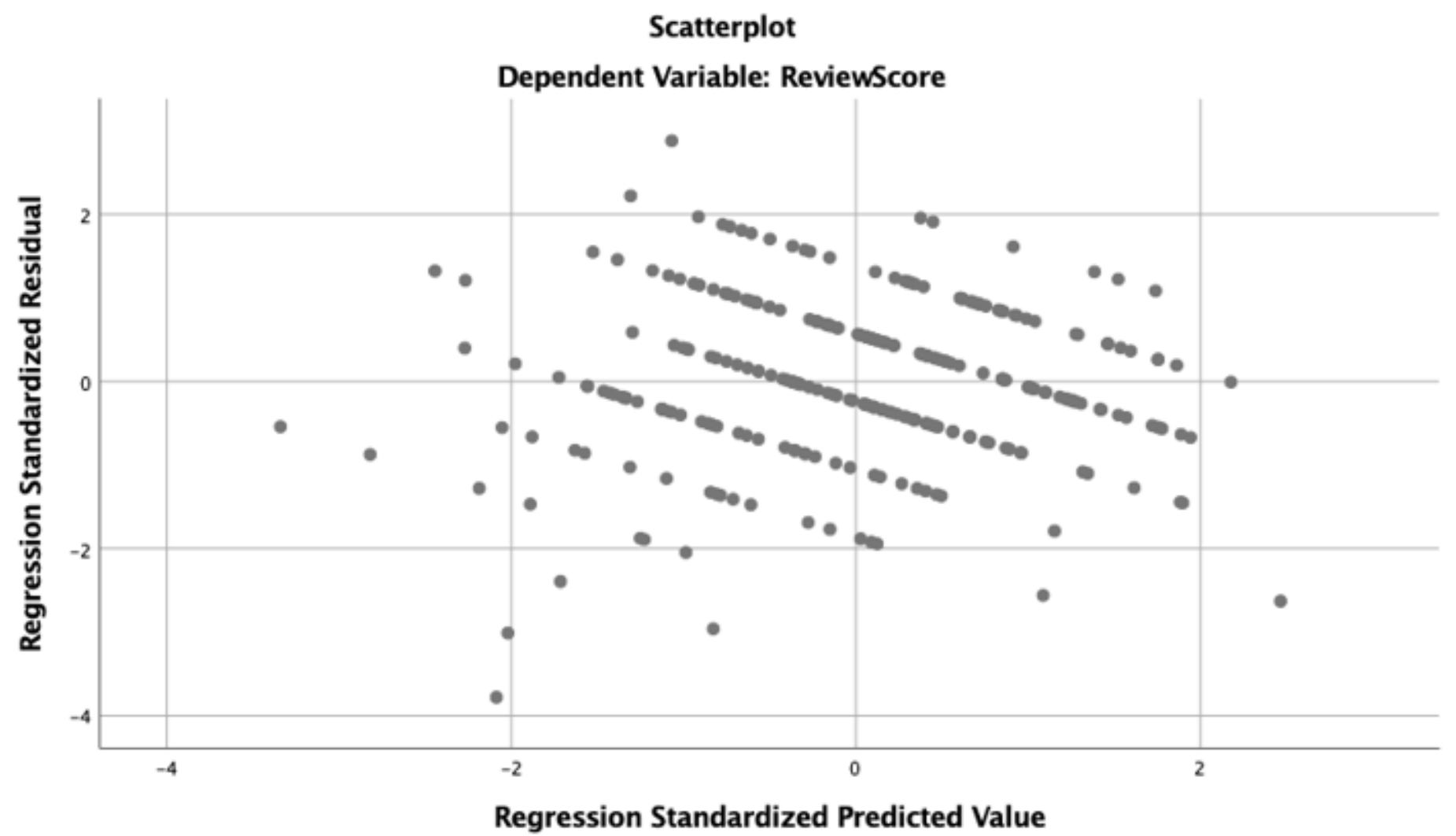

Figure 3

Scatterplot of the Data 